\title{
ESTRUTURAÇÃO DO PRIMEIRO NÚCLEO DA ABENGE ESTUDANTIL NO BRASIL
}

DOI: 10.37702/2175-957X.COBENGE.2021.3684

Vitória Bento Botelho - vivi.bbotelho@gmail.com

Instituto Mauá de Tecnologia

Rua Dona Avelina 119

04111-010 - São Paulo - SP

Octavio Mattasoglio Neto - omattasoglio@uol.com.br

Instituto Mauá de Tecnologia

Rua Tijuco Preto 933

03316-000 - São Paulo - SP

Resumo: Esse artigo é pesquisa-ação que apresenta a solução tomada para um problema da ABENGE (Associação Brasileira de Educação em Engenharia) e da ABENGE Estudantil que é a aproximação dos mesmos com os alunos das diversas faculdades de engenharia do Brasil, tornando seu trabalho mais conhecido e efetivo. A ABENGE Estudantil é um movimento de estudantes de graduação e/ou pós-graduação que busca a melhoria da educação em engenharia e tecnologia, escutando as necessidades dos cursos de graduação de todo o Brasil e trabalhando junto aos professores. Para resolver essa dificuldade a ABENGE Estudantil criou um projeto piloto para o desenvolvimento de núcleos em escolas de engenharia do país, chamados de Núcleos da ABENGE Estudantil (NAEs). Esse projeto tem o objetivo de ampliar, pragmatizar e contextualizar a causa, missão e objetivos da ABENGE Estudantil.

Palavras-chave: ABENGE, NAE, ENGINNERING. 


\section{ESTRUTURAÇÃO DO PRIMEIRO NÚCLEO DA ABENGE ESTUDANTIL NO BRASIL}

\section{INTRODUÇÃO}

Esse artigo é pesquisa-ação que apresenta a solução tomada para um problema da ABENGE (Associação Brasileira de Educação em Engenharia) e da ABENGE Estudantil que é a aproximação dos mesmos com os alunos das diversas faculdades de engenharia do Brasil, tornando seu trabalho mais conhecido e efetivo. A ABENGE Estudantil é um movimento de estudantes de graduação e/ou pós-graduação que busca a melhoria da educação em engenharia e tecnologia, escutando as necessidades dos cursos de graduação de todo o Brasil e trabalhando junto aos professores. Para resolver essa dificuldade a ABENGE Estudantil criou um projeto piloto para o desenvolvimento de núcleos em escolas de engenharia do país, chamados de Núcleos da ABENGE Estudantil (NAEs). Esse projeto tem o objetivo de ampliar, pragmatizar e contextualizar a causa, missão e objetivos da ABENGE Estudantil. Uma vez que, o Brasil possui diversas culturas e realidades financeiras diferentes, os NAEs entram para contribuir com a melhoria do ensino atuando de acordo com as necessidades de cada escola de engenharia. Os núcleos são formados pelos próprios alunos da escola, o que contribui para a velocidade das melhorias, já que os estudantes conhecem sua escola mais a fundo do que uma ABENGE Estudantil conseguiria, já que atua em todo o Brasil. Neste artigo será relatada a estruturação do primeiro NAE no Brasil.

\section{REFERENCIAL TEÓRICO}

A ABENGE Estudantil tem como visão ter até 2022, uma rede de associados com estudantes de todas as unidades federativas do Brasil, e que atuem como replicadores de suas ações. Essa associação preza pelo estudante enquanto agente ativo da realidade educacional em engenharia e incentiva seus membros a serem questionadores, buscando transformar sua realidade enquanto estudantes. Além disso, a coletividade e pluralidade são valores importantes, isso é prezar pelo trabalho em conjunto e celebrar a diversidade de pessoas e ideias, respectivamente. O plano piloto dos núcleos teve início em 2020. A ex-presidente da ABENGE Estudantil, Ingrid Andrade, visitou o Centro Universitário do Instituto Mauá de Tecnologia (CEUN-IMT), à convite do Professor Octavio Mattasoglio, a fim de promover uma conversa com os alunos e conhecer a faculdade. $O$ encontro tinha como tema as novas DCNs de engenharia homologadas em 2019 e teve um retorno muito positivo por parte dos alunos. Dessa forma, a Ingrid propôs a criação de um núcleo no CEUN-IMT. o que levou à formação do Núcleo na Mauá para que o trabalho da ABENGE Estudantil alcançasse as pessoas de forma mais direta. Além do Professor Octávio, outros alunos do CEUN-IMT participaram da organização para a visita da então presidente da ABENGE Estudantil e um dos alunos, Vitória Bento Botelho, se interessou na proposta da Ingrid e decidiu seguir em frente com o projeto e fundar o primeiro NAE do Brasil.

\subsection{A FORMAÇÃO DO NAE}

Primeiramente a Ingrid Andrade, ex-presidente da ABENGE Estudantil e o Marcus Vinícius Melo de Lyra, ex-vice-presidente da ABENGE Estudantil, sugeriram procurar mais 
alunos interessados no IMT. No dia 05 de Março de 2021 foi feita a primeira reunião com o Marcus, a Ingrid e mais 3 alunos da Mauá, incluindo a aluna Vitória Bento, onde a presidência sugeriu levantar uma lista com possíveis projetos que poderiam ser desenvolvidos no IMT de acordo com as necessidades da própria faculdade. Após 1 mês levantando ideias e com mais 2 membros, totalizando 5 alunos interessados na formação do Núcleo, foram passadas as ideias para a Ingrid e o Marcus, assim como para o Professor Octávio, que aceitou ser Professor Orientador do Núcleo. Os três projetos aprovados foram: projeto apoio aos alunos, projeto encontro nas escolas e projeto apoio a inovação. Com os projetos aprovados os alunos definharam a organização do Núcleo que seria vertical composta por presidência, diretores e membros. Importante ressaltar que cada núcleo pode escolher a sua forma de organização e os projetos que irão desenvolver, mas todos devem estar alinhados com os propósitos da ABENGE Estudantil.

\subsection{A ESTRUTURAÇÃO DO NAE}

O NAE começou a crescer e mais alunos estavam interessados em participar, por isso era importante oficializar essa nova entidade com a reitoria do CEUN-IMT. Vale apontar que a disposição de membros e cargos sofreu mudanças ao decorrer do estruturação do Núcleo, mas será apontado neste artigo a formatação final e mais relevante. Então, primeiramente, foram definidos os cargos: Presidente, Vice-presidente, Diretor de Projeto (um diretor para cada projeto), Diretor de Marketing e Diretor de Recursos Humanos. A presidência foi feita uma votação com a aluna Vitória Bento como presidente e o aluno Fernando Farah como vice-presidente, quanto a diretoria não ocorreu votação, mas sim foram preenchidos os cargos de acordo com a vontade e competência de cada membro. Em seguida, foi definido o nome e o logo dos núcleos, a sigla NAE (Núcleo da ABENGE Estudantil) foi definida pelo próprio Núcleo do CEUN-IMT e, assim como o logo (Figura 1), foram acolhidos pela ABENGE Estudantil como nome e logo oficial dos Núcleos. O Núcleo do CEUN-IMT adotou o nome oficial de NAE Mauá (Figura 2). A presidência da ABENGE Estudantil manteve uma reunião por semana com o NAE Mauá durante seis meses para apoiar a sua estruturação, ajudando com a formulação de documentos, capacitações e o que mais o Núcleo precisasse para se formar. Então, fomos para o próximo passo que era se tornar uma entidade oficial do CEUN-IMT, para isso foram redigidos um estatuto e regimento do NAE Mauá para serem entregues a reitoria que aprovou o projeto e apoiou o projeto. Dessa forma, o NAE Mauá se tornou oficialmente o primeiro Núcleo da ABENGE Estudantil no Brasil.

cronograma de reuniões para acompanhamento dos núcleos e, uma vez por mês, junta todos os núcleos do Brasil para conversar sobre seus projetos e/ou oferecer palestras para ajudar no conhecimento de todos. Atualmente, existem 11 Núcleos da ABENGE Estudantil espalhados pelo Brasil e a meta para a Diretoria da ABENGE Estudantil esse ano é aumentar esse número. 
Figura 1 - Logo dos NAEs

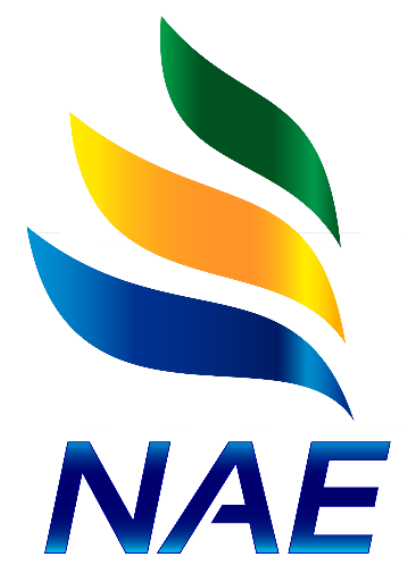

Fonte: NAE Mauá

Figura 1 - Logo dos NAE Mauá

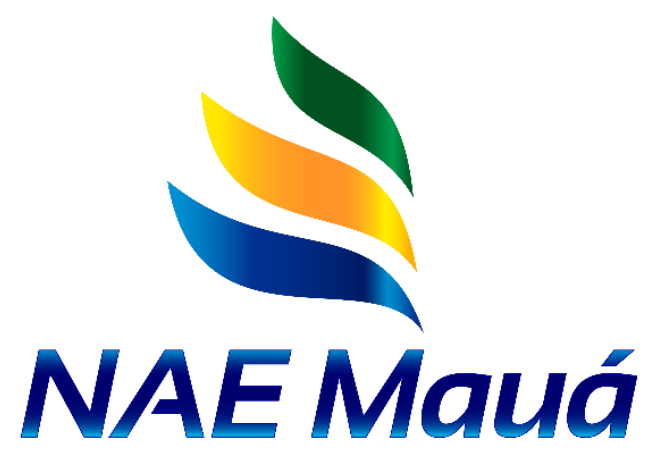

Fonte: NAE Mauá

\subsection{OS PROJETOS DO NAE MAUÁ}

Como dito anteriormente no item 2.1, foram aprovados 3 projetos, mas inicialmente o NAE Mauá começou com 2. Primeiro, o projeto Apoio aos Alunos que foi criado para facilitar a integração dos alunos e possibilitar um melhor aproveitamento da faculdade, tanto da parte estrutural quanto da acadêmica. Além disso, será possível um maior engajamento por parte dos alunos desde o início do curso. Nesse projeto são feitos encontros com os alunos sobre temas relevantes (sobre como organizar os estudos, por exemplo), atendimentos individuais, vídeos e portifólios informativos, etc. Tudo feito e coordenado por alunos veteranos do CEUN-IMT. O AAA foi criado com o intuito de fornecer total suporte para os alunos, para que assim eles possam ter a melhor experiência acadêmica. O segundo projeto é o encontro nas escolas (ENE), a intenção desse projeto é divulgar a graduação e o mercado de trabalho de engenharia e ajudar os alunos a escolherem suas carreiras com mais propriedade e consciência. Isso é possível por meio da troca de conhecimento entre os graduandos de engenharia do CEUN-IMT com os alunos participantes de escolas de ensino médio, além de dinâmicas que promovam o pensamento lógico e criativo que a engenharia proporciona. Com o ENE será possível desmistificar 
preconceitos, esclarecer dúvidas e fornecer informações sobre o curso de engenharia. Esse programa foi criado para ser, inicialmente, só para alunos que já estejam no ensino médio e, portanto, mais próximos de escolherem suas carreiras. Esses dois projetos foram desenvolvidos ao longo de 2020. O terceiro projeto, Apoio à Inovação (AI), só foi retomado no início de 2021, devido a sua complexidade. O projeto Al é relacionado com tecnologia e empreendedorismo e busca criar uma rede de alunos que participarão de encontros onde serão apresentados palestras e oficinas, tudo com o intuito de fomentar a inovação nas mentes dos alunos tornando eles mais criativos e incentivando eles a criarem os seus próprios projetos. Atualmente, em 2021, o NAE Mauá conta com 18 membros incluindo a diretoria e a presidência, além de contar com mais 10 Núcleos formados ao longo de 2020. Totalizando são 11 NAEs estruturados por todo o Brasil em 2021.

\section{MÉTODO DE PESQUISA}

O método de pesquisa escolhido para a realização deste trabalho de iniciação científica foi o de pesquisa-ação. Pesquisa-Ação é uma metodologia de pesquisa social, realizada associando aspectos teóricos da área pesquisada, com a prática de uma determinada ação ou resolução de problema coletivo, como forma de complementar a pesquisa. Essa metodologia permite que o pesquisador tenha parte na ação direta do que está sendo investigado, possibilitando que esse adquira o conhecimento ao mesmo tempo em que realiza a intervenção sobre a realidade. Em sumo, a Pesquisa-Ação busca unir a teoria com a prática, permitindo que o pesquisador participe de todas as etapas de um determinado projeto, trazendo benefícios tanto para o aprendizado do pesquisador, quanto para a execução do projeto, que pode ser realizado exatamente da forma que foi idealizado originalmente.

\section{CONSIDERAÇÕES FINAIS}

O NAE Mauá tem como objetivo incentivar os alunos a serem protagonistas em sua educação, a partir da criação de projetos para compartilhar informações e desenvolver habilidades que serão necessárias para a vida pessoal e profissional dos alunos. Com o Núcleo será possível proporcionar uma rede de comunicação mais efetiva entre os alunos e professores, de modo que o aluno possa se interessar mais pela sua educação e ser um participante ativo da mesma, juntamente com os esforços dos professores, contribuindo para a melhoria das estratégias e técnicas de ensino.

\section{REFERÊNCIAS}

Apresentadas em ordem alfabética e de acordo com a ABNT NBR 6023.

NETO, Octavio Mattasoglio.Pesquisa-Ação. 2009. Monografia. Acesso em: 09/05/2021

TRIPP, David.Pesquisa-Ação: Uma introdução metodológica. 2005. Monografia Universidade de Murdoch, Australia. Acesso em: 09/05/2021

Abstract: This article is an action research that presents a solution taken to a problem of ABENGE and ABENGE Estudantil that is the approximation of them with the students of the several engineering colleges in Brazil, making their work more known and effective. ABENGE Estudantil is a movement of undergraduate and / or graduate students that seeks to improve education in engineering and technology, listening to the needs of undergraduate courses throughout Brazil and working with teachers. To solve this difficulty, ABENGE 
Estudantil created a pilot project for the development of centers in engineering schools in the country, called ABENGE Estudantil Centers (NAEs). This project aims to expand, pragmatize and contextualize the cause, mission and objectives of ABENGE Estudantil.

Keywords: ABENGE, NAE, ENGINNERING. 